\title{
Reproduction in captive female Cape porcupines (Hystrix africaeaustralis)
}

\author{
R. J. van Aarde \\ Mammal Research Institute, University of Pretoria, Pretoria 0002, South Africa
}

\begin{abstract}
Summary. Captive females attained sexual maturity at an age of 9-16 months and conceived for the first time when 10-25 months old. Adult females were polyoestrous but did not cycle while lactating or when isolated from males. The length of the cycle varied from 17 to 42 days (mean \pm s.d. $31 \cdot 2 \pm 6 \cdot 5$ days; $n=43$ ) and females experienced $3-7$ sterile cycles before conceiving. Pregnancy lasted for 93-94 days ( $93.5 \pm 0.6$ days; $\mathrm{N}=4)$ and litter intervals varied from 296 to 500 days $(385 \pm 60 \cdot 4 ; n=10)$. Litter size varied from 1 to $3(1 \cdot 5 \pm 0 \cdot 66 ; n=165)$ and the well-developed precocial young weighed $300-440 \mathrm{~g}(351 \pm 47.4 \mathrm{~g} ; n=19)$ at birth. Captive females reproduced throughout the year with most litters $(78.7 \% ; n=165)$ being produced between August and March.
\end{abstract}

\section{Introduction}

Cape porcupines (Hystrix africaeaustralis) inhabit tropical forests, woodlands, grassland savannas, semi-arid and arid environments throughout southern Africa. Despite this widespread distribution little attention has been given to these nocturnal, Old World hystricomorph rodents, which shelter and breed in subterranean burrows, rock crevices and caves. Some information on reproduction in female porcupines has been published on the crested porcupine (H. cristata) (Weir, 1967), the Himalayan porcupine ( $H$. hodgsoni) (Gosling, 1980) and the Indian porcupine $(H$. indica) (Tohmé \& Tohmé, 1980). Mohr (1965) published incidental observations on animals of several species of Hystrix and Skinner, van Aarde \& van Jaarsveld (1984) reported on seasonal breeding in freeranging Cape porcupines. Information on related New World species has been reviewed by Weir (1974), who regarded the lengthy oestrous cycle and gestation period, occurrence of a vaginal closure membrane and lateral position of the nipples as characteristic features of reproduction in these rodents. Gestation lengths of porcupines have been recorded at 112 days (H. africaeaustralis: Dekeyser, 1955, in Weir, 1974), 105 days (H. hodgsoni: Gosling, 1980) and 'approximately three months' ( $H$. indica: Tohmé \& Tohmé, 1980). The length of the oestrous cycle varies from 30 to 37 days in crested porcupines (Weir, 1974) and Weir (1967) confirmed the presence of a vaginal closure membrane and the lateral position of the nipples in this species.

Seasonal breeding has been recorded for the Malayan porcupine ( $H$. brachyurus) and the Himalayan porcupine, with two breeding seasons per year being reported for Cape porcupines and a lack of seasonality in the Indian crested porcupine ( $H$. leucura) (see Weir, 1967). In captivity, however, Himalayan porcupines breed throughout the year (Gosling, 1980).

The present paper deals with aspects of female reproduction in Cape porcupines kept at the University of Pretoria's Experimental Farm $\left(25^{\circ} 45^{\prime} \mathrm{S} ; 28^{\circ} 12^{\prime} \mathrm{E}\right)$, South Africa.

\section{Materials and Methods}

The study colony was founded with porcupines donated by various zoological gardens, freeranging animals caught in their natural habitat and their descendants. Cape porcupines were 
housed in semi-outdoor concrete enclosures in groups of 2-5. Each enclosure was surrounded by a $1 \mathrm{~m}$ high brick wall and had an outdoor and roofed area with a floor space of $7.2 \mathrm{~m}^{2}$ and $11.3 \mathrm{~m}^{2}$ respectively. Porcupines were therefore exposed to natural conditions of illumination, ventilation and temperature and were fed daily on a mixture of fruit and vegetables of the season (van Aarde, 1985). The mean minimum daily temperature for the coldest month (July) was $4 \cdot 1^{\circ} \mathrm{C}$ and for the hottest month (January) $17.0^{\circ} \mathrm{C}$. Monthly mean maximum temperatures varied from $19 \cdot 1$ to $27.7^{\circ} \mathrm{C}$. Daylight duration varied from $10 \mathrm{~h} 35 \mathrm{~min}$ in June to $14 \mathrm{~h} 31 \mathrm{~min}$ in December (Buys, 1978).

Females were weighed and examined at 2-7-day intervals after immobilization through intramuscular injection of a mixture of ketamine hydrochloride (Ketalar: Parke-Davis Laboratories (Pty) Ltd, Isando, South Africa) and xylazine hydrochloride (Rompun: Bayer Pharmaceuticals (Pty) Ltd, Johannesburg, South Africa) at a mean \pm s.d. dose rate of $5.4 \pm 0.64 \mathrm{mg} / \mathrm{kg}$ and $1.5 \pm 0.23 \mathrm{mg} / \mathrm{kg}$ respectively. Handling was effected by herding porcupines into a crush-box designed for the purpose (see van Aarde, 1985). The length of the oestrous cycle was considered equivalent to the interval between the perforation of the vaginal closure membrane at one oestrus to the day before the onset of the following oestrus (Weir, 1974). Enclosures where females were kept were inspected daily for the presence of copulatory plugs.

Age at first oestrus was determined for 5 females born in captivity and examined at 5-day intervals from the age of 8 months. Gestation length was calculated as the interval between an observed copulation and parturition for 4 females kept isolated from intact males after copulation. Age at first conception was recorded for 9 females born in captivity; 4 of these were not immobilized until after parturition. All these females were housed with males that had sired offspring previously.

Date of birth, birth weight and litter size were recorded for all litters $(n=23)$ born in captivity and additional information was obtained from unpublished records kept by the National Zoological Gardens, Pretoria $(n=101)$, and the Johannesburg Municipal Zoological Gardens $(n=41)$. All means are given with one standard deviation ( \pm s.d.) of the mean.

\section{Results}

The oestrous cycle

Captive females were polyoestrous and nonlactating adults cycled throughout the year. Nine females examined systematically over a 1-year period exhibited $81.5 \%$ of the expected $(n=54)$ oestrous cycles, and the number of cycles observed during the periods of increasing $(n=22)$ and decreasing $(n=22)$ daylength did not differ significantly from that expected $\left(\chi^{2}=1.69\right.$ and 0.36 respectively).

The mean length of 43 oestrous cycles monitored in 12 females was $31.2 \pm 6.5(17-42)$ days, the majority $(60.5 \%)$ varying from 28 to 36 days. Extreme deviations from the mean reflected cycle lengths in nulliparous females with the greatest variation occurring during the pubertal period for 2 females. Mean length of 6 cycles monitored in parous females $(\mathbf{N}=2)$ housed with vasectomized males (35.5 \pm 3.6 days) did not differ significantly from that of parous females housed with intact males (32.3 \pm 4.6 days; $n=18$ ). Mean cycle length of 6 nulliparous females ( $30.5 \pm 7.3$ days; $n=19)$ also did not differ significantly from the mean observed in parous females (32.3 $\pm 6 \cdot 2$ days; $n=24)$.

The vaginal closure membrane remained perforated for a period of $8.8 \pm 3.9$ days $(n=34)$ and the copulatory plug was observed in the vagina on Days 3-8 (6.0 $\pm 1 \cdot 7$ days; $n=8)$ after the day of vaginal opening (Day 0 ). Copulation was observed 2-8 days after vaginal opening (5.0 $\pm 2 \cdot 6$ days; $n=8$ ) and, on two occasions when females were observed continuously, the copulatory plugs were expelled 45 and $48 \mathrm{~h}$ post coitum.

Three parous females isolated from males for 111-120 days did not exhibit oestrus (perforation 
of vaginal membrane) during that period, but perforation of the vaginal membrane occurred 5-12 days after the introduction of males to their enclosures.

Age at sexual maturity

Age at first oestrus varied from 273 to 552 days ( $413 \pm 118$ days; $\mathrm{N}=5$ ) when body weight was $11.0 \pm 1.3 \mathrm{~kg}$. None of these females conceived then and age at first conception varied from 298 to 864 days $(619 \pm 172$ days; $N=8)$ at a weight of $12.3 \pm 0.9 \mathrm{~kg}$. Females immobilized at irregular intervals before conception were significantly $(P<0.05)$ older $(24.2 \pm 3.8$ months; $\mathrm{N}=4)$ when conceiving for the first time than those not immobilized (16.4 \pm 4.5 months; $N=4)$. Nulliparous females $(\mathrm{N}=4)$ experienced 3-7 $(5 \cdot 8 \pm 2 \cdot 1)$ oestrous periods before conceiving, and ages at first oestrus and first conception were apparently not affected by month of birth.

\section{Pregnancy}

The mean length of gestation for 4 females separated from males on the day of copulation was $93.5 \pm 0.6(93-94)$ days. Weight gain during the first 50 days of pregnancy $(10.0-21.0 \mathrm{~g} /$ day $)$ was significantly less $(P<0.05$, paired $t$ test $)$ than during the second half of pregnancy $(16 \cdot 0-39 \cdot 0 \mathrm{~g} /$ day $)$.

\section{Litter size and weight at birth}

Litter size at birth in captivity varied from 1 to $3(1 \cdot 5 \pm 0 \cdot 66 ; n=165)$ with most litters $(58 \cdot 8 \%)$ being of singletons; $32 \cdot 1 \%$ were of twins and $9 \cdot 1 \%$ of triplets. Sex ratio at birth for 16 litters born in the University's captive colony was 1:1.53 (male:female; $n=23$ ) and did not deviate from unity $(P>0.05)$.

Weight at birth varied from 300 to $440 \mathrm{~g}(351 \pm 47.4 \mathrm{~g} ; n=19)$ and the mean weight of individual twins $(355 \pm 49.6 \mathrm{~g})$ did not differ significantly from that of singletons $(332 \pm 32.5 \mathrm{~g})$. The mean weight of 8 twins born alive also did not differ significantly from each other and males were not significantly heavier than females at birth.

Individual weight at birth was $2.1 \%$ of that of mean adult female weight $(12.9 \pm 1.8 \mathrm{~kg})$, while that of mean litter size, $4 \cdot 1 \%$, ranged from $2 \cdot 7$ to $8 \cdot 2 \%$. Neonatal weight in these porcupines was lower than that predicted by the significant linear relationship $(b=0.72, r=0.89)$ between neonatal litter weight $\left(\log _{10}\right)$ and maternal weight $\left(\log _{10}\right)$ calculated for 25 hystricomorph species, based on information that has been published by Weir (1974), Gosling (1980) and Tohmé \& Tohmé (1980).

\section{Lactation}

The mammary glands have a triangular shape and are situated in a lateral thoracic position posterior to the elbow of the forelimb. Two teats are placed centrally on each gland and no variation in teat number occurred in 130 females examined. Glands started to develop noticeably from 30 to 60 days after conception and milk could be expressed from the teats 42-60 days post coitum $(53 \pm 9.9$ days; $\mathrm{N}=3)$.

Young sucked while their mothers were in a crouching position and twins always sucked from opposite nipples. Nearly continuous teat contact during the first 2 weeks post partum was followed by intermittent contact for up to 20 weeks of age.

Maternal body weight decreased 4.0-20.0 g/day (13.5 $\pm 7.9 ; \mathrm{N}=4)$ during the first 60 days of lactation and individual decreases were not related to litter size. In considering the post-partum lactation period as the interval during which milk could be expressed manually from the nipples of immobilized females, the mean length of the lactation period was $101 \pm 37.8$ days (range 37-163; $n=9$ ). Normal cyclic activities began $2-42$ days after the cessation of lactation. 


\section{Litter intervals}

Ten litter intervals recorded for 8 females housed continuously with intact males varied from 296 to 500 days $(385 \pm 60 \cdot 4$ days). This was not affected by immobilization and the mean litter interval for 3 females immobilized during the litter interval was similar to that of 7 females that were not handled.

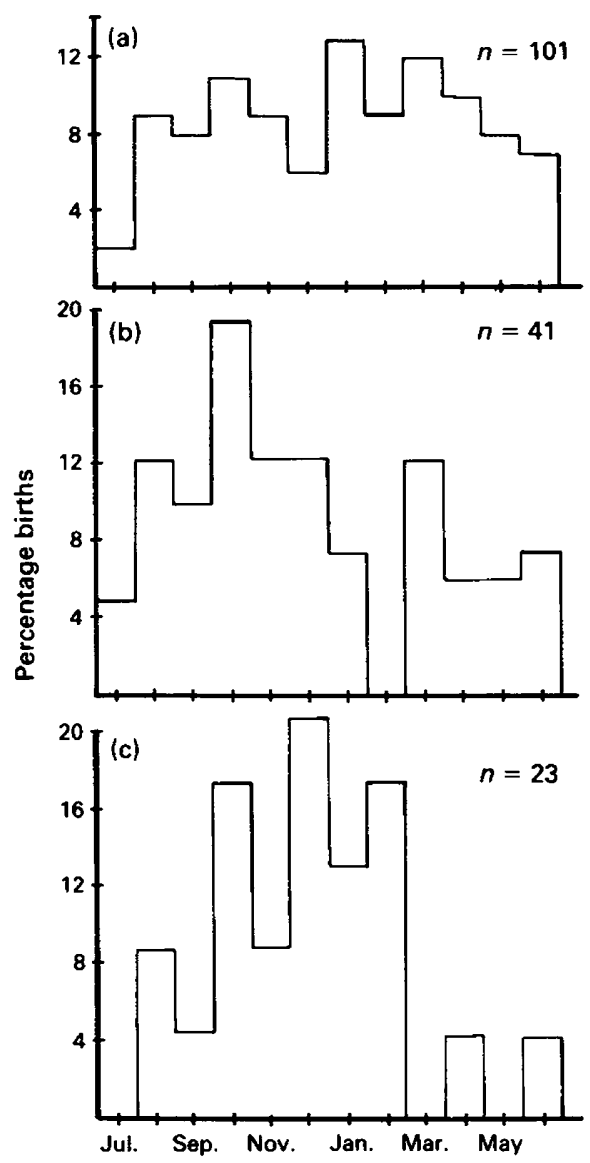

Text-fig. 1. The frequency distribution of births of Cape porcupines recorded in the National Zoological Gardens (a), the Johannesburg Municipal Zoological Gardens (b) and at the University of Pretoria (c).

\section{Seasonality}

The frequency distribution of births recorded in 3 captive groups indicates that porcupines breed throughout the year (Text-fig. 1), but most litters $(78 \cdot 7 \% ; n=165)$ were produced between August and March. This is significantly more than expected $\left(\chi^{2}=10.9 ; P<0.05\right)$ for the period. Mean dates of birth for these groups varied from 19 December to 8 January and the standard deviations of the birth dates from 73.3 to $96 \cdot 6$ days, thereby including $66 \cdot 3-82.6 \%$ of all births recorded. 


\section{Discussion}

Most research on hystricomorph rodents until now has been conducted on New World species and it is apparent that several unusual reproductive patterns occur within this group (Weir, 1974; Weir \& Rowlands, 1974). Reproductive characteristics of the female Cape porcupine are similar to those suggested as typical for hystricomorph rodents as a group (see Weir, 1974).

The presence of a vaginal closure membrane, which usually only perforates at oestrus and parturition, provides a ready means of determining periodicity of the reproductive cycle. This membrane has been recorded in all hystricomorphs studied so far, except the coypu, Myocastor coypus (Weir, 1974). Rowlands \& Weir (1977) regarded the perforation of this membrane as an 'external indicator of ovulation' and synchronization of perforation with regular surges of oestradiol-17 $\beta$ concentrations in peripheral blood in the porcupine confirmed this (van Aarde, 1984). Perforation of the vaginal closure membrane has also occurred during pregnancy (Day 52 post coitum) in a Cape porcupine, as has been reported for the green acouchi (Myoprocta pratti: Kleiman, 1970), guinea-pig, degu (Octodon degus), tuco-tuco (Ctenomys spp.) and plains viscacha (Lagostomus maximus: Weir, 1974). Female Cape porcupines isolated from males remained in anoestrus, but the introduction of a male resulted in the onset of oestrus within 12 days. These females were continuously exposed to the odours produced by males (males housed in pens next to the females), thus suggesting that actual physical contact between the sexes is required to initiate cyclic ovarian activity. Most female cuis (Galea musteloides) also do not experience spontaneous cycles when isolated from males (Rood \& Weir, 1970; Weir, 1973a) and behavioural as well as pheromonal mechanisms may be involved in initiating cyclic ovarian activity in porcupines.

Gestation lengths reported here (93-94 days) were accurately measured since they were based on calculations of the interval between observed matings and normal parturition with pregnant females isolated from fertile males during that interval. Previous reports of 112 days (Dekeyser, 1955, in Weir, 1974) are therefore probably erroneous. Long gestation periods in hystricomorphs apparently are related to the extremely slow rate of prenatal growth, particularly in the early stages of pregnancy (Roberts \& Perry, 1974).

The inhibition of oestrous activity during the extended period of lactation has been confirmed by histological examination of ovaries from lactating females and the consistently depressed plasma progesterone concentrations during lactation (van Aarde, 1984). Lactation anoestrus is not unusual for hystricomorph rodents and occurs in the chinchilla (Weir, 1973b), the wild guinea-pig (Rood \& Weir, 1970), green acouchi (Weir, 1971a) and plains viscacha (Weir, 1971b).

Neonatal litter weight in hystricomorph rodents increases with an increase in maternal weight at a rate similar to that observed for 22 mammalian groups by Tuomi (1980). Neonatal weight in Cape porcupines was within the limits $(300-465 \mathrm{~g})$ recorded by Mohr (1965) for the genus, but much lower than the $1000 \mathrm{~g}$ listed for crested porcupines by Weir (1974). Litter weight at birth, expressed as a percentage of maternal weight is high in New World hystricomorphs (11-60\%; Weir, 1974) but low in the Old World species (from 3.2\% in Himalayan porcupines (Gosling, 1980) to $14.4 \%$ in the greater cane rate, Thryonomys swinderianus (based on data in Smithers, 1983)). The low values recorded for Hystrix may be ascribed to their relatively siort gestation period when compared to New World species of comparable size. Litter intervals recorded here are much longer than the 91 days reported by Mohr (1965) for African porcupines ( $H$. africaeaustralis and $H$. cristata) and the 142 days recorded by Gosling (1980) for Himalayan porcupines. Their observations suggest that there is a post-partum oestrus and/or that during lactation females may come into oestrus and are fertile. This discrepancy cannot be explained.

Free-ranging Cape porcupines in the Karoo reproduce seasonally with the peak in their birth season coinciding with peaks in rainfall and presumably primary productivity (Skinner et al., 1984). Birth dates deduced for 2 pregnant females collected in the winter rainfall area of South Africa confirm this, suggesting that primary production may be an ultimate factor affecting reproductive activities (van Aarde, 1984). Seasonal breeding may be attributed to the seasonal occurrence of 
oestrus but captive porcupine females housed with intact males do exhibit oestrous cycles throughout the year, with the intensity of cyclic activity not being affected by daylength. However, cyclic activities are affected by lactation, which renders females anoestrous for about 3-4 months and is thus a limiting factor in female productivity. The social and physiological mechanisms underlying the 3-7 infertile cycles after lactation are not known but, together with gestation and lactation periods, results in a litter interval of about 1 year. Therefore, a hypothetical female conceiving at a specific time during a mating season will conceive presumably always at about the same time during the following season. The length of the lactation period and the number of sterile cycles after lactation would serve as variables enhancing seasonality, with these probably being affected by temperature and rainfall (Skinner et al., 1984). The lack of seasonality in the 3 captive populations, that were maintained under natural conditions but which were provided with a relatively constant food supply, confirms this suggestion.

This study was part of a wider doctoral study under the supervision of Professor J. D. Skinner. Financial support was provided by the University of Pretoria, the Council for Scientific and Industrial Research and the Wildlife Society of Southern Africa who twice awarded me the Charles Astley Maberly Memorial Scholarship.

\section{References}

Buys, M.E.L. (1978) Duration of daylight in South Africa. Technical Communication. Department of Agricultural Technical Services. Republic of South Africa.

Gosling, L.M. (1980) Reproduction of the Himalayan porcupine (Hystrix hodgsoni) in captivity. J. Zool., Lond. 192, 546-549.

Kleiman, D.G. (1970) Reproduction in the female green acouchi, Myoprocta pratti Pocock. J. Reprod. Fert. 23, 55-63.

Mohr, E. (1965) Altweltiche Stachelschweine. A. Zeimsen, Wittenberg Lutherstadt.

Roberts, C.M. \& Perry, J.S. (1974) Hystricomorph embryology. Symp. zool. Soc. Lond. 34, 333-360.

Rood, J.P. \& Weir, B.J. (1970) Reproduction in female wild guinea-pigs. J. Reprod. Fert. 23, 393-409.

Rowlands, I.W. \& Weir, B.J. (1977) The ovarian cycle in vertebrates. In The Ovary, 2nd edn, Vol. II, Ch. 6, pp. 217-273. Eds S. Zuckerman \& B. J. Weir. Academic Press, New York.

Skinner, J.D., van Aarde, R.J. \& van Jaarsveld, A.S. (1984) Adaptations in three species of large mammals (Antidorcas marsupialis, Hystrix africaeaustralis, Hyaena brunnea) to arid environments. S. Afr. J. Zool. 19, 82-86.

Smithers, R.H.N. (1983) The Mammals of the Southern African Subregion. University of Pretoria, Pretoria.

Tohmé, G. \& Tohmé, H. (1980) Contribution à l'ètude du porc-épic Hystrix indica-indica Kerr, 1792 (Rodentia). Mammalia 44, 523-529.

Tuomi, J. (1980) Mammalian reproductive strategies: a generalized relation of litter size to body size. Oecologia 45, 39-44. van Aarde, R.J. (1984) Reproduction in the porcupine Hystrix africaeaustralis Peters. D.Sc. thesis, University of Pretoria.

van Aarde, R.J. (1985) Husbandry and immobilization of captive porcupines Hystrix africaeaustralis. S. Afr. J. Wildl. Res. 15, (in press).

Weir, B.J. (1967) Aspects of reproduction in some hystricomorph rodents. Ph.D. thesis, University of Cambridge.

Weir, B.J. (1971a) Some observations on reproduction in the female green acouchi, Myoprocta pratti. $J$. Reprod. Fert. 24, 193-201.

Weir, B.J. (1971b) The reproductive physiology of the plains viscacha, Lagostomus maximus. J. Reprod. Fert. 25, 355-363.

Weir, B.J. (1973a) The role of the male in the evocation of oestrus in the cuis, Galea musteloides (Rodentia: Hystricomorpha). J. Reprod. Fert., Suppl. 19, $421-432$.

Weir, B.J. (1973b) The induction of ovulation and oestrus in the chinchilla. J. Reprod. Fert. 33, 61-68.

Weir, B.J. (1974) Reproductive characteristics of hystricomorph rodents. Symp. zool. Soc. Lond. 34, 265-301.

Weir, B.J. \& Rowlands, I.W. (1974) Functional anatomy of the hystricomorph ovary. Symp. zool. Soc. Lond. 34, 303-332. 